\title{
Between Myths and Facts: The Contribution of Exchange Experiences to the Professional Development of Teachers
}

\author{
Bruno Leutwyler, ${ }^{1, *}$ \\ ${ }^{1}$ Institute for International Cooperation in Education IZB, PH Zug - University of Teacher Education, Zug, \\ Switzerland \\ *Correspondence: Institute for International Cooperation in Education IZB, PH Zug - University of Teacher \\ Education, Zugerbergstrasse 3, CH-6301 Zug, Switzerland. Tel: 41-41-727-1273 E-mail: bruno.leutwyler@phzg.ch
}

Received: September 29, 2014

Accepted: October 27, $2014 \quad$ Online Published: November 14, 2014

doi:10.5430/jct.v3n2p106

URL: http://dx.doi.org/10.5430/jct.v3n2p106

\begin{abstract}
This contribution provides an overview of different facets that can be developed or promoted in exchange stays and that are specific for teachers. By systematizing the available findings with a conceptual approach, it assigns the majority of the findings to three different facets of teaching-specific 'intercultural competencies': It indicates a potential to develop professional knowledge, teaching-specific beliefs as well as motivational orientations that allow students to engage actively in challenging intercultural situations. The overview uncovers a range of methodological constraints in the prevailing literature and reveals an urgent need to add more solid evidence specifically in the context of teacher education.
\end{abstract}

Keywords: study abroad program; teacher education; intercultural education; student exchange; international field experience; professional development

\section{Introduction}

Exchange programmes are becoming increasingly popular. They represent one of the strongest and most popular pillars in the attempt to integrate global, intercultural and international perspectives into higher education institutions and are perceived at times as 'the heart of internationalization' (Hahn, 2004) or as 'the face of internationalization' (Knight, 2012). Against this background, it is not surprising that the number of exchange students has shown a steady rise in the last decades. In the European Union, the number of exchange students participating in the ERASMUS exchange programme (EuRopean community Action Scheme for Mobility of University Students, a European Union student exchange programme established in 1987) has increased from 3244 in the academic year 1987/88 to 190498 in 2010/11 (European Commission, 2012). In the USA, the participation in study abroad programmes has more than tripled over the past two decades (Institute of International Education, 2012) and is still conceived as one of the "top 10 trends in higher education" (Mahon, 2010, p. 8). Against this background, some scholars estimate the number of academic publications about study abroad during the last decade at more than one thousand (cf. Vande Berg, Paige, \& Lou, 2012, p.3).

Two goals are pursued when students participate in exchange programs: On the one hand, from the institutional perspective, exchange programmes promise to provide an important contribution to the internationalisation of the university or college environment. On the other hand, from the individual perspective, exchange programmes also aim to contribute to the development of the individual participants. Accordingly, the participation in exchange programs is mostly promoted by pointing at the huge personal benefits that might be expected.

However, such expectations correspond much more to a programmatic nature than to solid empirical evidence. The available evidence regarding the impacts of exchange programmes suggests rather potentialities than tangible effects. An overview of the specific literature on individual effects of student mobility highlights the biggest potential in terms of personality development, foreign language proficiency and intercultural sensitivity (e.g. Bachner \& Zeutschel, 2009; Bracht et al., 2006; Kehm, 2005a; Paige \& Vande Berg, 2012; Vande Berg, 2009; Vande Berg, Connor-Linton, \& Paige, 2009; Vande Berg, Paige, \& Lou, 2012). This is reflected in the finding that "personal growth and identity development", "language learning and acquisition" and "intercultural competence and 
development" are three of the five most often researched issues regarding study abroad, besides issues on administration and policy as well as on recruitment, participation and re-entry (Streitwieser, Le, \& Rust, 2012).

In regard to personal development, a development of independence and flexibility as well as an increase in self-esteem and sociability has been reported (Eichhorn, Feroiu, Marin, \& Ollinger, 2002). Former participants attribute such development processes to exchange programmes even after considerable temporal distance: Ten years after participating in an exchange programme, former exchange students still believe to have benefited in many cognitive, affective, behavioural and social domains, such as in self-efficacy, self-confidence, persistence, open-mindedness and openness toward foreign attitudes and customs (Franklin, 2010; Thomas, 1999). Bachner and Zeutschel (2009) show that former exchange students attribute personal growth and maturation to their exchange stays even several decades later; and the comprehensive SAGE-study documents long-term manifestations of global engagement, revealing that for most of the former exchange students, the study abroad period was one of the most important experiences they had during their college years with a strong impact on their further lives (Paige, Fry, Stallman, Josić, \& Jon, 2009). Even though the empirical basis of these findings is mainly based on self-reports which from a methodological point of view are not unproblematic (see below) - the available studies suggest that exchange programmes have lasting effects on the personal development of the participants.

Concerning language skills, the findings also seem to be clear: The enhancement of foreign language competency is considered one of the most evident and definite effects of exchange programmes and has been empirically identified multiple times (Bracht et al., 2006; Kehm, 2005; Vabø, 2007; Vande Berg, 2009; Vande Berg, Connor-Linton, \& Paige, 2009). The sustainability of this effect, however, depends on being able to carry on using the respective language after return - this is still possible for more than one third (38\%) of the participants four years after an ERASMUS study stay (Bracht et al., p. 73).

With reference to intercultural sensitivity, available findings show a less consistent picture. Indeed, most studies point out the large potential that during the participation in an exchange programme, different aspects of intercultural sensitivity and cultural empathy can develop, prejudices can be broken down, and fears to engage with foreign cultures can be reduced (for an overview see Perry \& Southwell, 2011; Pettigrew, 2004; Pettigrew, Tropp, Wagner, \& Christ, 2011). However, some empirical evidence suggests that not all students benefit to the same degree in this regard and that the fact of being in a foreign context does not automatically lead to a beneficial development (Anderson, Lawton, Rexeisen, \& Hubbard, 2006; Hammer, 2005; Jackson, 2009; Stronkhorst, 2005; Sutton \& Rubin, 2010; Vande Berg, 2009; Vande Berg, Connor-Linton, \& Paige, 2009; Williams, 2005).

To sum up, the effectiveness of exchange programmes has been extensively researched in relation to general individual effects. Job-related effects are, in contrast, mentioned less or deal with economic aspects such as the duration of study and of the first job search, or the amount of the first salary after the studies (Bracht et al., 2006; Jahr, Schomburg, \& Teichler, 2002; Messer \& Wolter, 2007; Teichler \& Janson, 2007). Effects regarding specific studies refer to general achievement gains (Sutton \& Rubin, 2010) or to the development of study-specific self-confidence regarding time-management during studies or regarding the mastery of independent seminar projects (Schweisfurth, 2012).

In relation to teacher education, professional benefits may include personal development including more self-confidence, increased openness for foreign attitudes, more flexibility, broadened foreign language skills, and a pronounced intercultural sensitivity. The importance of these competencies and attitudes is indisputable for teachers - they are not, however, teaching-specific competencies or attitudes.

The question of whether future teachers can also benefit specifically for their profession is, however, relevant in different respects. Firstly, teacher education programmes at universities are based, usually, on the strict separation of general education and teaching-specific training. Considering this background, the question must be raised as to what exchange stays during the studies contribute to the teaching-specific training - and not only to general education and maturation. Secondly, from an economic point of view, the organization of exchange programmes requires a substantial financial investment for universities of teacher education, so that the question of financial accountability arises. Thirdly, whenever the discussion arises about the value of exchange programmes in teacher education, ample ambitions are postulated with exaggerated expectations regarding the effects of international student mobility. Alternatively, the lack of teaching-specific key information during the absence is lamented - two different expressions of the fact that acknowledgement of the value and usefulness of international experiences in teacher education is not based on solid evidence. In fact, a clear overview is missing of what might legitimately be expected from participation in an exchange programme in teacher education.

In view of this, this contribution proposes a structure for the growing literature on the benefits of exchange 
programmes in teacher education. It aims at providing an overview of different facets that can be developed or promoted during an exchange stay and that are specific for teachers. In doing so, it firstly sketches a structural framework that allows for an appropriate arrangement of the different findings. It then reports the key findings from the available literature within this structural framework. Finally, it summarizes these findings and discusses the implications for the design of exchange programmes as well as for further research.

\section{Teaching-Specific Effects of Student Mobility}

In the last decade, a growing body of literature has started to address the question of whether participating in exchange programmes actually influences teaching-specific competencies and attitudes. However, the different contributions are based on very different experiences: Some of the papers operate with the term 'study abroad', others with 'exchange stay', 'student mobility programme' or 'international field experience'. The different terms in use do not correspond to clearly distinguishable programme designs and seem to be interchangeable - at least to some extent. With this in mind, the following overview considers contributions covering all these different terms and compounds different designs of programmes regarding duration, sorts of immersion or embedding at home or abroad. Notwithstanding, the relevant commonalities consist of (a) the common target groups of pre-service and in-service teachers, and (b) the common character of the programmes abroad as elements of an institutionalised study course and requiring school-based experiences with direct observations of classroom-teaching, discussions with local colleagues or autonomous teaching sequences.

Considering these rather diverse empirical bases, the following patterns arise. Some studies dealing with the effects of exchange programmes specifically in teacher education replicate the above mentioned findings on general effects (personal development, language skills and intercultural sensitivity), however, they barely contribute to the question of teaching-specific effects: They replicate the general effects in the context of teacher education (for an overview see Cushner, 2009). With regard to teaching-specific effects, the vast majority of the literature suggests a benefit with regard to teaching-specific facets of intercultural competencies. Only few contributions point to other aspects that might be furthered by participating in an exchange programme.

\subsection{Facets of Teaching-Specific Intercultural Competencies}

Regarding the benefits of exchange stays for teaching-specific facets of intercultural competencies, the literature assembles very different approaches and concepts. They all relate to the fuzzy term of 'intercultural learning' and represent a broad, multifaceted and partly incoherent field of research, including many anecdotal approaches. Therefore, a sharp picture of what might be seen as 'state of the art' regarding intercultural learning in exchange stays is difficult to obtain. Against this background, the following overview of the literature tries to systematize the available findings with a conceptual approach. To do so, it draws on an understanding of 'intercultural competence' that involves cognitive, emotional, motivational and volitional dimensions (Deardorff, 2009; Perry \& Southwell, 2011). Furthermore, it combines this understanding with a conceptualisation of teaching competencies as a conglomerate of professional knowledge, beliefs (with inherent values and norms), and motivational orientations (Baumert \& Kunter, 2006; Klieme \& Hartig, 2008). With regard to the teaching context, intercultural competence involves, in this sense,

- $\quad$ specific facets of professional knowledge (e.g. about migration flows, traditions of religious minorities, peculiarities of second language acquisition or culture- and country-specific knowledge as well as the cultural construction of schooling)

- beliefs that stimulate productive learning processes for all pupils (whether they come from a dominant culture or not)

- motivational orientations that allow for actively engaging in challenging intercultural situations

- Following this approach, the variegated literature on benefits of exchange stays for teaching-specific facets of intercultural competencies may be organized as outlined in the following section.

\subsubsection{Awareness of Cultural Imprints in Schooling and Teaching}

As a specific facet of professional knowledge that would be fostered in exchange stays, many studies refer to a more elaborated understanding of how one's own schooling and teaching practices are culturally imbued. This can be seen, for instance, in the research on a short-term study abroad program for US-American pre-service teachers in Honduras, tracking 54 participants before, during and after their international teaching experience (JoAnn Phillion \& Malewski, 2011; JoAnne Phillion, Malewski, Sharma, \& Wang, 2009; Sharma, Phillion, \& Malewski, 2011). The authors 
conclude that participants would develop a "sense of importance of critically examining one's own culture, recognizing the assumptions and stereotypes that structure and limit the success of ethnic minorities, students of color, and immigrant children" (JoAnn Phillion \& Malewski, 2011, p. 655). This would lead to a higher sensitivity for the relevance of ethnicity, race, class or gender issues in teaching and would help the participants to become aware of what it means to be "the White normative majority in relation to minority groups" (Phillion, Malewski, Sharma, \& Wang, 2009, p. 334).

Another study suggests that during their immersion programme in New Zealand teacher students from Hong Kong become aware of how Hong Kong and New Zealand teachers use different communication and didactical strategies and how they group pupils according to differing criteria (Lee, 2009; 2011). Generally, pre-service teachers gain "the opportunity to use their experiences of difference to question professional practice in their own culture [...], thereby acquiring [...] critical cultural awareness" (Newman, Taylor, Whitehead, \& Planel, 2004, p. 290). This critical cultural awareness would imply the perception of cultural imprints on learning approaches, classroom organization, expectations of pupils, parents and teachers and on assessment practices (ibid.). The same critical cultural awareness is highlighted in the study of Flannery Quinn, Morton and Brindley (2011), who traced reflective journals and tutors' observations of 17 US-American pre-service teachers during four-week internships in England. With their hermeneutic approach, they suggest that the experience of being an "outsider" (p. 39) helped them to reflect on different school and teaching practices and to recognize, thereby, peculiarities of their own familiar school system (see also Brindley, Quinn, \& Morton, 2009; with reference to the concepts of 'consonance' and 'dissonance'; likewise Nero, 2009; Santoro \& Major, 2012; Walters, Garii, \& Walters, 2009; Wormnaes, 2008). Dantas (2007), who used an ethnographic approach to trace 22 US-American pre-service teachers during an international teaching experience in Brazil, concludes in this regard: "Study-abroad experiences [...] offer another context to prepare teachers by building their [...] understanding of the arbitrariness of perceived cultural norms. [...] Students had to learn to read a world that did not fit their expectations, which made visible their invisible assumptions of cultural norms and beliefs" (p. 88). In the same sense, Marx and Moss (2011) summarize their finding based on a case study of one pre-service teacher from the US-American context who spent one semester in England: "Such study abroad teacher education programs are offered as an innovative means to promote preservice teachers' intercultural development, providing unique opportunities for these students to confront their ethnocentric worldviews and begin to consider the ways culture influences teaching and learning" (p. 35). Similarly Roose (2001, p. 45) concludes her findings by claiming that that participants learnt about "a range of education systems and the effect of culture on the way schools function and what students learn". She maintains that they developed, in this sense, an "understanding [of] school as a "culture" (ibid.). Regarding their future role as teachers, findings drawing on journal entries and written assignments of 8 US-American pre-service teachers completing a teaching experience in Spain suggest that they develop "a greater awareness of themselves as communicative and cultural beings" (Colon-Muniz, SooHoo, \& Brignoni, 2010, p. 68).

Finally, Leutwyler \& Lottenbach (2011) analysed the experiences of 75 former exchange students in teacher education. They identified students' enhanced awareness of their own normality conceptions as a key benefit, although they showed that not all exchange students developed this awareness to the same extent. Therefore, Leutwyler \& Lottenbach suggest a four-stage model for the reflection of normality that proposes different levels to reflect on one's own conceptions of schooling and teaching as culturally imbued: a culture-blind reflection, a culture-bound reflection, a culture-relative reflection and a culture-dynamic reflection.

\subsubsection{Changes in Teachers' Beliefs}

In addition to these facets of professional knowledge, the literature suggests that exchange stays would also influence teachers' beliefs about teaching in culturally diverse contexts. In this regard, Kambutu and Nganga (2008) speak of an increased cultural appreciation of foreigners among US-American teachers who spent a few weeks in Kenyan schools. An American study of 15 student teachers from the USA who completed a four week internship in Italy suggests a greater appreciation of cultural heterogeneity in school classes (Pence \& Macgillivray, 2008). Willard-Holt (2001) asserts that among 27 student teachers from the USA who spent one week in a Mexican school there was a partial reduction in prejudice against Mexican school classes.

The US-American study of Wiggins, Follo and Eberly (2007) suggests that teaching in different cultural contexts could be very generally beneficial when dealing with children from cultural minorities. This finding is also highlighted in the study of Tang and Choi (2004), who conducted a case study with four pre-service student teachers in an international field experience programme. Chieffo and Griffiths (2004) point out in this context that teachers show more patience with foreign-language speaking students after a stay abroad. A similar finding is reported by 
Marx and Pray (2011), who analysed reflective essays of ten pre-service teacher students that had spent three weeks in a study abroad programme in Mexico. They conclude that "their experiences [...] made them much more empathetic" to the needs of foreign-language speaking students (p. 523). Lee (2011) reports very generally on the basis of retrospective interview data with 15 student teachers from Hong Kong, stating that "their intercultural sensitivity and openness to cultural diversity were enhanced" (p. 17) as a result of a six-week immersion experience in New Zealand.

Colon-Muniz et al. (2010) claims that the experience of cultural dissonance results in student teachers developing more empathy towards immigrant pupils. In this regard, a study of 50 US-American student teachers that participated in an overseas student teaching experience suggests that, as a key effect of this experience, participants benefited in terms of their beliefs about teaching in culturally diverse contexts (see also Cushner \& Mahon, 2002; Mahon \& Cushner, 2002). Based on reports of their own experiences during the stay abroad and on retrospective self-assessments of the participants after the stay abroad, the authors believe that participants perform "more strongly in multicultural education" and understand better "the need to attend to individual differences as well as include students' personal experiences in the learning process" (Mahon \& Cushner, 2002, p. 7). They cite one participant in particular: "The biggest change that happened to me was that I became much more multicultural in my view of the world. I believe that multicultural education happens every day, and that this can become a mindset for the teacher rather than an occasional effort. I owe this to my overseas teaching experience" (ibid., p. 7). The above-mentioned study of Sharma et al. also suggests that a teaching experience abroad encourages examining and critically reflecting on one's own beliefs and stereotypes and helps "to identify and build upon the strengths of different cultures rather than view minority students as a problem that needs to be fixed" (Sharma, Phillion, \& Malewski, 2011, p. 20). In the same sense, participants in a cross-cultural teaching experience report that the major effect was "their attraction to differences" (Roose, 2001, p. 46) and that, as a result, they included more materials from other cultures and content about other cultures.

Finally, the study of Gilson and Martin (2010) shows what school administrators think about the specific potential of teachers with pre-service teaching experience abroad. The results suggest that a majority of school administrators think that these teachers show an "increased respect for diverse cultures" and that they would be "more tolerant and understanding of educational differences" (ibid., p. 7). This finding clearly shows that changes in teachers' beliefs in the sense of a stronger appreciation of cultural diversity in schools - is perceived as a key benefit of exchange experiences in teacher education not only by the participants themselves, but also by staff who were not involved in an exchange experience.

\subsubsection{Strengthening Motivational Orientations}

In addition to different facets of professional knowledge and to teachers' beliefs, the literature suggests that exchange stays would also influence teachers' motivational orientations that allow student teachers to engage actively in challenging intercultural situations. In this regard, Rapoport (2008) draws on interviews with 35 Russian and US-American teachers who participated in different exchange programmes and claims that, by participating in an exchange programme, teachers show more interest in the cultural background of their pupils. The afore-mentioned study of Willard-Holt (2001) suggests that the 27 student teachers from the USA who spent one week in a Mexican school felt more prepared to work with children from different backgrounds. In the same sense, Leutwyler \& Lottenbach's 2011 study (see above) asserts that completing an internship in a country where many migrants come from enhances the students' self-efficacy beliefs for dealing with pupils with a migrant background. In this regard, the study by Santamaria et al. (2009) shows how a one-month stay of pre-service and in-service US-American teachers in Mexican schools makes these participants feel better prepared to "connect with groups of culturally similar people in the United States" and to better "empathize with students and parents of Mexican descent" (p. 48).

To sum up, the existing literature portrays a rich picture of teaching-specific facets of intercultural competencies that may be developed by an exchange stay. The awareness of cultural imprints in schooling and teaching may be raised, teachers' beliefs may be changed towards more appreciation of cultural diversity in schools; and the motivational orientations that allow for actively engaging in challenging intercultural situations may be fostered. In addition to these facets of intercultural competencies, some studies suggest other teaching-specific benefits.

\subsection{Teaching-Specific Self-Efficacy Beliefs}

Regarding teaching-specific benefits other than facets of intercultural competencies, some studies suggest a benefit in terms of teaching-specific self-efficacy beliefs: For instance, Garii (2009) suggests that an international teaching experience furthers the flexibility in teaching and increases the "comfort and ability to work with ambiguity and uncertainty" (p. 97). On the basis of eight US-American or Canadian teachers' retrospective reflections about an 
international teaching experience during their early career in a U.S. accredited school abroad, Garii maintains that this experience contributes to "increased self-confidence" (ibid.) in teaching. The study of Scoffham and Barnes (2009), which documents the impact of a four-week internship of English pre-service teachers in Indian schools, shows how "students became increasingly responsible and autonomous during the study visit" (p. 260). The authors conclude that the huge number of dissonances experienced - in emotional, cognitive and existential terms empowered the pre-service teacher students to deal with challenging situations. The above mentioned study of Pence and Macgillivray (2008) suggests, in addition to the greater appreciation of cultural heterogeneity, higher professional self-esteem as a result of the internship abroad. In the same sense, the above-mentioned study on 50 US-American student teachers who participated in an overseas student teaching experience also gives evidence that teaching-specific self-efficacy beliefs are fostered during teaching experience abroad (Cushner \& Mahon, 2002; Mahon \& Cushner, 2002). Based on reports of their experiences during the stay abroad and on retrospective self-assessments of the participants after the stay abroad, the authors conclude: "Through facing their personal anxieties and testing their own limitations, students create a space for opportunity and empowerment. In that space, they report the growth of self-confidence and esteem, increased adaptability, resourcefulness, and persistence" (Mahon \& Cushner, 2002, p. 5).

Another approach is adopted in the study of Roose (2001). She analyses the reflections of five practicing teachers who, during their pre-service teacher training, completed an internship abroad. These reflections were collected with quite some temporal distance (in some case several years), but in return they put a specific focus on what these teachers think about how their experience influenced their actual teaching now. Based on this rather anecdotal data, Roose claims that these five teachers became more self-confident due to their international experience.

An additional perspective is provided in the study of Sahin (2008) on 26 Turkish student teachers who completed a two-month internship in the United States, including a six-week student teaching experience in high schools. In addition to the Turkish students' self-assessment, the US-American mentors who supervised the Turkish students during their student teaching experience also assessed the impact of the internship on the students. Their qualitative assessments were consistent with those of the students themselves. They reported that "student teachers became more independent, more self-motivated, and more self-confident in their teaching" (ibid., p. 1785).

Finally, the above mentioned study of Gilson and Martin (2010) suggests that a majority of school administrators think that teachers with pre-service teaching experience abroad show a greater personal ambition and self-confidence and are better prepared to resolve unexpected issues.

To sum up, in addition to the potential benefits with regard to facets of intercultural competencies, the enhancement of teaching-specific self-efficacy beliefs seems to be another important asset of international experiences in teacher education.

\subsection{Further Benefits}

Only very few contributions point to other aspects that might be furthered by participating in an exchange programme. One of these aspects might be labelled as global orientation in teaching. Willard-Holt (2001), following 27 student teachers from the USA who spent one week in a Mexican school (see above), reports that many of these students integrated experiences from their Mexico stay into their teaching. She sums up these findings with a reference to a global dimension: "This represents a conceptual change toward a more global perspective in their teaching" (ibid., p. 515). The development of global awareness is also the key finding of an early case study by McKay and Montgomery (1995), who traced four US-American student teachers during international placements.

Another aspect that is reported in some studies is the potential to develop teaching-specific flexibility. Analogously to the general, non-teaching-specific development of independence and flexibility (see introduction above), it is argued that teaching or presenting in a foreign and unfamiliar context fosters the ability to deal with unexpected situations and, thereby, supports the participants to become more flexible in teaching (Cushner \& Mahon, 2002; Garii, 2009; Gilson \& Martin, 2010; Mahon \& Cushner, 2002; Scoffham \& Barnes, 2009). Finally, the above-mentioned study of Leutwyler \& Lottenbach (2011) raises another aspect that might be positively affected during an exchange experience: the potential to increase one's own motivation to teach. In this regard, they cite one Swiss student who completed an internship in France: "I am really looking forward to teaching. I want to implement how I could do things better, and I believe I can do it better" (ibid., p. 77). Another statement with similar content read: "I was reminded what is amazing about 'being a teacher'. In this respect, my career choice was confirmed" (ibid.). 


\section{Discussion and Conclusion}

This contribution aimed to provide an overview of different facets that can be developed or promoted during an exchange stay and that are specific for teachers. It assigned the large majority of the available findings to three different facets of teaching-specific 'intercultural competencies'. Firstly, as an expression of professional knowledge, participating in an international exchange programme provides the opportunity for a student teacher to develop knowledge of and awareness about the cultural construction of schooling and teaching. Secondly, as an expression of beliefs, participating in an international exchange programme may foster the appreciation of cultural diversity in schools. Thirdly, as an expression of motivational orientations that allow for actively engaging in challenging intercultural situations, participating in an international exchange programme may promote self-efficacy beliefs which are helpful in dealing with cultural diversity in schools.

In addition to these facets of teaching-specific 'intercultural competencies', a considerable amount of literature suggests that participating in an international exchange programme enhances teaching-specific self-efficacy beliefs. Finally, some occasional papers hint at the potential to develop a global orientation in teaching, improve teaching-specific flexibility and increase of one's own motivation to teach.

On the basis of this overview, it should be possible to moderate between the extreme poles of exaggerated expectations regarding the effects of international student mobility on the one hand, and the fear of missing fundamental teaching-specific key information during the absence or a simple trivialisation with regard to the resisting power for modifying action-guiding cognitions on the other hand. However, this overview might not provide a basis for a solid assessment of what can legitimately be expected from participation in an exchange programme in teacher education. This is due to the fact that the available literature, in general, is not founded on solid empirical ground. The majority of the reported findings emerge from data in the form of retrospective causal attribution: Former exchange students retrospectively attribute the reported effects to their experiences during their exchange stays. This method is problematic when the diverse and complex interdependences of pre-conditions and process experiences are taken into account. In light of this, the 'causal sequence problem' (Pettigrew, 2004, p. 772) has to be taken seriously. For example, to what extent was a student teacher's ability and willingness to reflect on cultural imprints of schooling developed before the exchange stay and to what extent did this ability develop during the exchange stay? Furthermore, to what extent was an already developed ability and willingness to reflect on cultural imprints a driver and motivating factor to apply for a respective programme? This is hardly reliably measurable by an ex post subjective evaluation. Given this causal sequence problem, we do not have a reliable empirical basis to assess the actual effects of exchange experiences.

In addition to this causal sequence problem, the available literature lacks a systematic comparison of what could have been learnt or developed at home. Of all the cited studies on teaching-specific effects, only one study adopted a quasi-experimental approach and compared learning experiences abroad with those at home. However, this study of Pray and Marx (2010) covered only awareness of peculiarities of second-language-acquisition, and only nine students with an exchange experience were involved. This empirical data does not allow for an assessment of whether a study abroad experience is more effective in facilitating other developments than simply offering courses with the equivalent content at the home institution. Given this lack of systematic comparisons, we do not know what the additional effects of exchange programmes are - it might be hypothesized that the same learning experiences could be made during an analogous course in the home institution, for instance with an internship in culturally very diverse classrooms or in communities of minority groups.

Furthermore, Vande Berg, Paige and Lou (2012, p. 21ff) give some more reasons why the many enthusiastic statements of former exchange students, such as "this time abroad really transformed me", cannot be taken as evidence for tangible effects. Firstly, they point out that we do not rely on self-reports to assess student learning in other domains. Too often, the discrepancy between the subjectively experienced effectiveness (or the corresponding belief) on the one hand and the concrete, tangible development of specific competencies on the other hand is too big to be disregarded. Secondly, they claim that ordinary students do not normally have enough knowledge and insight into the complex topics of intercultural learning and are, therefore, unable to draw valid conclusions about it. Thirdly, they note that respective statements might be influenced by a social desirability bias.

To sum up, different methodological constraints make it impossible to sketch a clear 'state-of-the-art' picture regarding teaching-specific 'effects' of exchange stays. A lack of solid studies is evident. For this reason, further research on student exchange in teacher education should be conducted, but must deal with the following two methodological challenges. Firstly, further research should include measurements or assessments of learning outcomes beyond simple retrospective self-assessments, for instance by adding baseline-data on the given issue 
before the participants start their international experiences, or by adding additional perspectives to those of the students. Secondly, further research should consider the question of whether or how learning processes in exchange settings differ from those at home, for instance by tracing control groups for an analogous period of time at their home institution.

Given the methodological constraints in many of the studies cited, the implications for further research seem to be evident. However, what does the state-of-the-art imply for teacher education and programme design? Even though the research situation is rather limited, a clear tendency does emerge. An important aspect seems to be that teaching-specific effects are only reported when the participants have the opportunity to immerse themselves in the daily school routine of the host culture. The available evidence seems to suggest that the potential for a teaching-specific benefit increases when (pre-service or in-service) teachers are involved in occupational activities (either as a participant or as an observer), provided they have the opportunity to teach at least some units in the foreign context themselves, or if they have the opportunity to observe daily school routines and discuss what they have observed with local counterparts. These opportunities are key elements in international field experiences. However, this contribution also considered literature on exchange experiences of pre-service teachers in so called 'exchange stays' and 'student mobility programmes'. In the latter the involvement in occupational activities is not always given or has to be incorporated with special negotiations.

Furthermore, the available literature does indeed indicate domains of potential - different domains which contain a potential to be developed and promoted in exchange experiences. A clear overview of these domains of potential show what respective programmes should be designed for. It is only possible to conceptualize and implement optimal support for participants if it is clear what is expected of and strived for in an exchange experience. In this regard, a comprehensive programme design should address questions of the appropriate preparations before, individual coaching and supervision during, and teaching-specific debriefing and wrap-ups after an exchange experience. Meanwhile, there is a strong consensus that unguided, non-structured personal experiences during an exchange stay do not automatically materialise into tangible effects - even less so if it comes to teaching-specific developments. A comprehensive programme design should, moreover, address questions about relevant individual pre-conditions so that productive developments in exchange stays can be maximised. In this regard, pre-conditions such as openness for new things, interest in the unfamiliar or ambiguity tolerance might be considered. However, a clear list of necessary pre-conditions is hardly definable because too many factors in different configurations can influence productive learning in cross-cultural encounters. Current research approaches focus, therefore, rather on identifying inhibitive or obstructive factors, which hinder productive developments (Pettigrew, 2004; Pettigrew, Tropp, Wagner, \& Christ, 2011). In this regard, it is not surprising that the question about the selection of the participants for exchange programmes in teacher education is seldom discussed.

To conclude, the overview of the available literature indicates different domains of potential. It suggests that neither a one-sided idealisation with exorbitant and exaggerated expectations regarding the effects on the one hand, nor a simple trivialisation with regard to the resisting power for modifying action-guiding cognitions on the other, will do justice to the actual relevance of exchange experiences. Furthermore, the overview reveals an urgent need to add more solid evidence of effects, specifically in the context of teacher education, and to consider the preconditions, at both the individual and institutional levels, for productive developments in exchange experiences - a need that has to be addressed in further contributions.

\section{References}

Anderson, P. H., Lawton, L., Rexeisen, R. J., \& Hubbard, A. C. (2006). Short-term study abroad and intercultural sensitivity: A pilot study. International Journal of Intercultural Relations, 30(4), 457-469.

Bachner, D., \& Zeutschel, U. (2009). Long-term effects of international educational youth exchange. Intercultural Education, 20 (4 supp 1), 45-58.

Baumert, J., \& Kunter, M. (2006). Stichwort: Professionelle Kompetenz von Lehrkräften. Zeitschrift für Erziehungswissenschaft, 9(4), 469-520.

Bracht, O., Engel, C., Janson, K., Over, A., Schomburg, H., \& Teichler, U. (2006). The professional value of ERASMUS mobility. Kassel: International Centre for Higher Education Research (INCHER-Kassel).

Brindley, R., Quinn, S., \& Morton, M. L. (2009). Consonance and dissonance in a study abroad program as a catalyst for professional development of pre-service teachers. Teaching and Teacher Education, 25(3), 525-532. 
Chieffo, L., \& Griffiths, L. (2004). Large-Scale Assessment of Student Attitudes After a Short-Term Study Abroad Program. Frontiers: The interdisciplinary journal of study abroad, 10, 165-177.

Colon-Muniz, A., SooHoo, S., \& Brignoni, E. G. B. (2010). Language, culture and dissonance: a study course for globally minded teachers with possibilities for catalytic transformation. Teaching Education, 21(1), 61-74. http://dx.doi.org/10.1080/10476210903466976

Cushner, K. (2009). The Role of Study Abroad in Preparing Globally Responsible Teachers. In R. Lewin (Ed.), The Handbook of Practice and Research in Study Abroad (pp. 151-169). New York: Routledge.

Cushner, K., \& Mahon, J. (2002). Overseas Student Teaching: Affecting Personal, Professional, and Global Competencies in an Age of Globalization. Journal of Studies in International Education, 6(1), 44-58. http://dx.doi.org/10.1177/1028315302006001004

Dantas, M. L. (2007). Building teacher competency to work with diverse learners in the context of international education. Teacher Education Quarterly, 34(1), 74-94.

Deardorff, D. K. (2009). Synthesizing Conceptualizations of Intercultural Competence: A Summary and Emerging Themes. In D. K. Deardorff (Ed.), The SAGE Handbook of Intercultural Competence (pp. 265-270). Thousand Oaks: SAGE Publications.

Eichhorn, M., Feroiu, R., Marin, R., \& Ollinger, J. (2002). Persönlicher und volkswirtschaftlicher Nutzen des ERP-Stipendiums Materialien und Beiträge zur Europäischen Wirtschaftspolitik, Nr. 19. Trier: Universität Trier.

European Commission. (2012). ERASMUS - Facts, Figures \& Trends. The European Union support for student and staff exchanges and university cooperation in 2010-11. Luxembourg: Publications Office of the European Union.

Flannery Quinn, S. M., Morton, M. L., \& Brindley, R. (2011). A window of opportunity: perspectives of preservice teachers from the United States on the customs and practices of teaching in primary schools in England. Teacher Development, 15(1), 37-52. http://dx.doi.org/10.1080/13664530.2011.555223

Franklin, K. (2010). Long-term Career Impact and Professional Applicability of the Study Abroad Experience. Frontiers: The interdisciplinary journal of study abroad, 19, 169-191.

Garii, B. (2009). Interpreting the Unfamiliar: Early Career International Teaching Experiences and the Creation of the Professional Self. Journal of Curriculum Theorizing, 25(3), 84-103.

Gilson, T. W., \& Martin, L. C. (2010). Does Student Teaching Abroad Affect Teacher Competencies? Perspectives From Iowa School Administrators. Action in Teacher Education, 31(4), 3-13.

Hahn, K. (2004). Die Internationalisierung der deutschen Hochschulen. Kontext, Kernprozesse, Konzepte und Strategien. Wiesbaden: VS Verlag für Sozialwissenschaften.

Hammer, M. R. (2005). Assessment of the impact of the AFS study abroad experience. New York: AFS Intercultural Programs, Inc.

Institute of International Education. (2012). Open Doors 2011: Report on International Educational Exchange. New York: Institute of International Education, Inc.

Jackson, J. (2009). Intercultural learning on short-term sojourns. Intercultural Education, 20(4 supp 1), 59 - 71.

Jahr, V., Schomburg, H., \& Teichler, U. (2002). Internationale Mobilität von Absolventinnen und Absolventen europäischer Hochschulen Werkstattberichte 61. Kassel: Wissenschaftliches Zentrum für Berufs- und Hochschulforschung der Universität Kassel.

Kambutu, J., \& Nganga, L. W. (2008). In these uncertain times: Educators build cultural awareness through planned international experiences. Teaching and Teacher Education, 24(4), 939-951.

Kehm, B. M. (2005a). The contribution of international student mobiltiy to human development and global understanding. US-China Education Review, 2(1), 18-24.

Kehm, B. M. (2005b). Mit SOKRATES II zum Europa des Wissens. Ergebnisse der Evaluation des Programms in Deutschland. Kassel: Wissenschaftliches Zentrum für Berufs- und Hochschulforschung.

Klieme, E., \& Hartig, J. (2008). Kompetenzkonzepte in den Sozialwissenschaften und im erziehungswissenschaftlichen Diskurs. Zeitschrift für Erziehungswissenschaft, 10(Sonderheft 8), 11-29. 
Knight, J. (2012). Student Mobility and Internationalization: trends and tribulations. Research in Comparative and International Education, 7(1), 20-33.

Lee, J. F. K. (2009). ESL student teachers' perceptions of a short-term overseas immersion programme. Teaching and Teacher Education, 25(8), 1095-1104.

Lee, J. F. K. (2011). International Field Experience - What Do Student Teachers Learn? Australian Journal of Teacher Education, 36(10), 1-22.

Leutwyler, B., \& Lottenbach, S. (2011). Reflection on Normality: The Benefits of International Student Exchange for Teacher Education. In T. Goetz, G. Jaritz \& F. Oser (Eds.), Pains and Gains of International Mobility in Teacher Education (pp. 59-78). Boston, Taipei, Rotterdam: Sense Publishers.

Mahon, J. (2010). Fact or fiction? Analyzing institutional barriers and individual responsibility to advance the internationalization of teacher education. Teaching Education, 21(1), 7-18.

Mahon, J., \& Cushner, K. (2002). The Overseas Student Teaching Experience: Creating Optimal Culture Learning. Multicultural Perspectives, 4(3), 3-8. http://dx.doi.org/10.1207/s15327892mcp0403_2

Marx, H., \& Moss, D. M. (2011). Please Mind the Culture Gap: Intercultural Development During a Teacher Education Study Abroad Program. Journal of Teacher Education, 62(1), 35-47.

Marx, S., \& Pray, L. (2011). Living and learning in Mexico: developing empathy for English language learners through study abroad. Race Ethnicity and Education, 14(4), 507-535. http://dx.doi.org/10.1080/13613324.2011.558894

McKay, J. W., \& Montgomery, J. (1995). Changes in perceptions: A comparative study of the experiential learning of international student teachers. Paper Presented at the Annual Meeting of the American Educational Research Association, San Francisco, CA. (ERIC Document Reproduction Service No. ED 384 582).

Messer, D., \& Wolter, S. C. (2007). Are student exchange programs worth it? Higher Education, 54(5), 647-663.

Nero, S. (2009). Inhabiting the other's world: language and cultural immersion for US-based teachers in the Dominican Republic. Language, Culture and Curriculum, 22(3), 175-194. http://dx.doi.org/10.1080/07908310903203066

Newman, E., Taylor, A., Whitehead, J., \& Planel, C. (2004). 'You just can't do it like that—it's just wrong!' Impressions of French and English trainee primary teachers on exchange placement in primary schools abroad: the value of experiencing the difference. European Journal of Teacher Education, 27(3), 285-298.

Paige, M. R., \& Vande Berg, M. (2012). Why Students Are and Are Not Learning Abroad. A Review of Recent Literature. In M. Vande Berg, M. R. Paige \& K. H. Lou (Eds.), Stundet Learning Abroad. What Our Students Are Learning, What They're Not, and What We Can Do About it (pp. 29-58). Sterling: Stylus Publishing.

Paige, R. M., Fry, G. W., Stallman, E. M., Josić, J., \& Jon, J.-E. (2009). Study abroad for global engagement: the long-term impact of mobility experiences. Intercultural Education, 20(sup1), S29-S44. http://dx.doi.org/10.1080/14675980903370847

Pence, H. M., \& Macgillivray, I. K. (2008). The impact of an international field experience on preservice teachers. Teaching and Teacher Education, 24(1), 14-25.

Perry, L. B., \& Southwell, L. (2011). Developing intercultural understanding and skills: models and approaches. Intercultural Education, 22(6), 453-466. http://dx.doi.org/10.1080/14675986.2011.644948

Pettigrew, T. F. (2004). Intergroup contact. Theory, research, and new perspectives. In J. A. Banks \& C. McGee Banks (Eds.), Handbook of research on multicultural education (pp. 770-781). San Francisco: John Wiley \& Sons.

Pettigrew, T. F., Tropp, L. R., Wagner, U., \& Christ, O. (2011). Recent advances in intergroup contact theory. International Journal of Intercultural Relations, 35(3), 271-280. http://dx.doi.org/10.1016/j.jintrel.2011.03.001

Phillion, J., \& Malewski, E. (2011). Study Abroad in Teacher Education: Delving into Cultural Diversity and Developing Cultural Competence. Action in Teacher Education, 33(5-6), 643-657. http://dx.doi.org/10.1080/01626620.2011.627310

Phillion, J., Malewski, E., Sharma, S., \& Wang, Y. (2009). Reimagining the Curriculum: Future Teachers and Study Abroad. Frontiers: The interdisciplinary journal of study abroad, 18, 323-339. 
Pray, L., \& Marx, S. (2010). ESL Teacher Education Abroad and at home: A cautionary tale. The Teacher Educator, 45(3), 216-229. http://dx.doi.org/10.1080/08878730.2010.488099

Rapoport, A. (2008). Exchange programs for educators: American and Russian perspectives. Intercultural Education, 19(1), 67-77.

Roose, D. (2001). White Teachers' Learning about Diversity and "Otherness": The Effects of Undergraduate International Education Internships on Subsequent Teaching Practices. Equity \& Excellence in Education, 34(1), 43-49. http://dx.doi.org/10.1080/1066568010340106

Sahin, M. (2008). Cross-cultural experience in preservice teacher education. Teaching and Teacher Education, 24(7), 1777-1790.

Santamaria, L. J., Santamaria, C. C., \& Fletcher, T. V. (2009). Journeys in Cultural Competency: Pre-Service U.S. Teachers in Mexico Study-Abroad Programs. Diaspora, Indigenous, and Minority Education, 3(1), 32-51. http://dx.doi.org/10.1080/15595690802584166

Santoro, N., \& Major, J. (2012). Learning to be a culturally responsive teacher through international study trips: transformation or tourism? Teaching http://dx.doi.org/10.1080/10476210.2012.685068

Schweisfurth, M. (2012). Are Sojourners Natural Comparativists? Critical Perspectives on the Learning Experiences of International Students. Research in Comparative and International Education, 7(1), 81-89.

Scoffham, S., \& Barnes, J. (2009). Transformational experiences and deep learning: the impact of an intercultural study visit to India on UK initial teacher education students. Journal of Education for Teaching: International research and pedagogy, 35(3), 257 - 270.

Sharma, S., Phillion, J., \& Malewski, E. (2011). Examining the practice of critical reflection for developing pre-service teachers' multicultural competencies: findings from a study abroad program in Honduras. Issues in Teacher Education, 20, 9-22.

Streitwieser, B. T., Le, E., \& Rust, V. (2012). Research on Study Abroad, Mobility, and Student Exchange in Comparative Education Scholarship. Research in Comparative and International Education, 7(1), 5-19.

Stronkhorst, R. (2005). Learning Outcomes of International Mobility at Two Dutch Institutions of Higher Education. Journal of Studies in International Education, 9(4), 292-315. http://dx.doi.org/10.1177/1028315305280938

Sutton, R. C., \& Rubin, D. L. (2010). Documenting the Academic Impact of Study Abroad: Final Report of the GLOSSARI Project. Paper presented at the NAFSA Annual Conference, Kansas City, Missouri.

Tang, S., \& Choi, P. (2004). The development of personal, intercultural and professional competence in international field experiences in initial teacher education. Asia Pacific Education Review, 5(1), 50-63.

Teichler, U., \& Janson, K. (2007). The Professional Value of Temporary Study in Another European Country: Employment and Work of Former ERASMUS Students. Journal of Studies in International Education, 11(3-4), 486-495. http://dx.doi.org/10.1177/1028315307303230

Thomas, A. (1999). Welche langfristigen Wirkungen haben internationale Schüleraustauschprogramme? In Internationaler Jugendaustausch- und Besucherdienst der Bundesrepublik Deutschland (Ed.), Forum Jugendarbeit International - Südosteuropa (pp. 193-209). Münster: Votum Verlag GmbH.

Vabø, A. (2007). Evaluation of the Leonardo da Vinci and SOCRATES programmes in Norway. Oslo: NIFU STEP Studier av innovasjon, forskning og utdanning (Studies in Innovation, Research and Education).

Vande Berg, M. (2009). Intervening in student learning abroad: a research-based inquiry. Intercultural Education, 20(sup1), S15-S27. http://dx.doi.org/10.1080/14675980903370821

Vande Berg, M., Connor-Linton, J., \& Paige, M. R. (2009). The Georgetown Consortium Project: Interventions for Student Learning Abroad. Frontiers: The interdisciplinary journal of study abroad, 18, 1-75.

Vande Berg, M., Paige, M. R., \& Lou, K. H. (2012). Student Learning Abroad. Paradigms and Assumptions. In M. Vande Berg, M. R. Paige \& K. H. Lou (Eds.), Stundet Learning Abroad. What Our Students Are Learning, What They're Not, and What We Can Do About it (pp. 3-28). Sterling: Stylus Publishing.

Walters, L. M., Garii, B., \& Walters, T. (2009). Learning globally, teaching locally: incorporating international exchange and intercultural learning into pre-service teacher training. Intercultural Education, 20(sup1), S151-S158. http://dx.doi.org/10.1080/14675980903371050 
Wiggins, R. A., Follo, E. J., \& Eberly, M. B. (2007). The impact of a field immersion program on pre-service teachers' attitudes toward teaching in culturally diverse classrooms. Teaching and Teacher Education, 23(5), 653-663.

Willard-Holt, C. (2001). The impact of a short-term international experience for preservice teachers. Teaching and Teacher Education, 17(4), 505-517.

Williams, T. R. (2005). Exploring the Impact of Study Abroad on Students' Intercultural Communication Skills: Adaptability and Sensitivity. Journal of Studies in International Education, 9(4), 356-371. http://dx.doi.org/10.1177/1028315305277681

Wormnaes, S. (2008). Exploring the potential for facilitating reflection through cross-cultural collaboration in teacher education. In N. Popov, C. Wolhuter, B. Leutwyler, M. Kysilka \& J. Ogunleye (Eds.), Comparative Education, Teacher Training, Education Policy and Social Inclusion (pp. 82-85). Sofia: Bureau for Educational Services. 